\title{
CONFERÊNCIA ANUAL DA REAL SOCIEDADE DE GEOGRAFIA E DO INSTITUTO DOS GEÓGRAFOS BRITÂNICOS - 1999
}

Alina Esteves ${ }^{1}$

Subordinada ao tema As Geografias do Futuro, realizou-se mais uma Conferência Anual da Real Sociedade de Geografia e do Instituto dos Geógrafos Britânicos (Royal Geographical Society - Institute of British Geographers). A conferência teve lugar entre os dias 4 e 7 de Janeiro na cidade inglesa de Leicester, localizada 150 quilómetros a NNW de Londres, e foi organizada pelo Departamento de Geografia da Universidade de Leicester. A conferência contemplava ainda três subtemas que revelam grande pertinência para a Geografia actual: a centralidade versus marginalidade, a etnicidade e a observação da Terra.

A apresentação das 470 comunicações inscritas repartiu-se por 50 sessões de trabalho distribuídas por três dias. As sessões organizaram-se segundo 29 Grupos de Investigação ou de Estudo (Research Groups e Study Groups). Estes reúnem os participantes de acordo com os seus interesses em termos científicos, com o intuito de aprofundar e divulgar os resultados da investigação. $\mathrm{Na}$ Conferência deste ano foi notável o número de sessões conjuntas, não só pelas conexões existentes entre os diversos temas, mas também porque a organização motivou o intercâmbio de resultados.

O Grupo de Investigação de Geomorfologia e a Associação Britânica de Climatólogos promoveram uma sessão conjunta, repartida por quatro módulos, onde se discutia a relação entre as alterações climáticas e as transformações ocorridas na superfície terrestre, nomeadamente nas variações do nível do mar, o acentuar da desertificação do Sahel e a erosão do solo em vários pontos do globo. Os investigadores salientaram a necessidade de desenvolver modelos que permitam prever os efeitos resultantes das modificaçóes climáticas, no sentido de evitar desastres humanos e melhorar a qualidade de vida das populações das regiões mais afectadas. O Grupo de Investigação de Biogeografia organizou, em colaboração com o Grupo de Estudo de Biogeografia da União Geográfica Internacional, uma sessão sobre as abordagens ecológicas da paisagem focando as transformações espaciais dos ecossistemas na República da Arménia, a

\footnotetext{
1 Assistente da Faculdade de Letras, Universidade de Lisboa. Investigadora do Centro de Estudos Geográficos (endereço do CEG no início do volume). E-mail: aesteves@esoterica.pt
} 
variação espacial de espécies arbóreas da floresta tropical no Belize, a distribuição dos enclaves de savana no sul da Nigéria e a necessidade de usar séries temporais longas baseadas em informação de satélite e em teledetecção para compreender a evolução de alguns dos fenómenos estudados.

O Grupo de Investigação Ambiental focalizou a sua atenção na recuperação dos rios europeus, no aumento da acidez das águas doces e no impacto que a construção de recifes por parte do Homem tem no ambiente.

Os Grupos de Investigação da Geografia Política e das Áreas em Desenvolvimento organizaram duas sessões de trabalho: a primeira, sobre as transformações políticas e sociais ocorridas no período que medeia entre a 2. ${ }^{a}$ Guerra Mundial e o final do século, onde foi dado particular destaque ao trabalho das Organizações Não Governamentais; a segunda sessão versou o período de transição que a África do Sul está a viver após o fim do regime de apartheid, nomeadamente as dificuldades que a população negra enfrenta no exercício da cidadania, no acesso à posse de bens de raiz e a empregos com melhor remuneração.

As questões da mortalidade e da saúde foram abordadas na sessão conjunta dos Grupos de Investigação da Geografia da População e da Geografia da Saúde, mais precisamente o papel da habitação e do contexto socio-espacial, e o acesso ao transporte próprio na definição de níveis de stress ao longo da vida do indivíduo e consequentemente na sua longevidade.

A sessão do Grupo de Investigação dos Métodos Quantitativos esteve mais vocacionada para os Sistemas de Informação Geográfica e a utilidade destas ferramentas na análise espacial e na actividade de consultoria que os geógrafos podem oferecer a outras áreas do saber científico.

Os problemas da privatização de alguns meios de transporte, da pendulação da população suburbana, da viabilidade comercial dos autocarros em áreas suburbanas e da criação de transportes integrados, foram discutidos na sessão de trabalho do Grupo de Investigação da Geografia dos Transportes.

Os Grupos de Investigação da Geografia Histórica e da Geografia Social e Cultural promoveram uma sessão sobre as paisagens e identidades do mundo Celta onde abordaram as questões da mercadorização do mundo Celta através do turismo em espaço rural, a construção das identidades galesa, escocesa e irlandesa ao longo dos séculos e o papel do novo Parlamento escocês na representação oficial da nação.

O Grupo de Investigação do Planeamento e Ambiente organizou uma sessão dedicada à exclusão social e à justiça ambiental que primou pela variedade de comunicações. Foram apresentados resultados de investigações feitas sobre o modo como a privatização da água pode gerar exclusão social, sobre a proximidade entre infra-estruturas industriais poluentes e áreas residenciais de população de baixo rendimento e sobre a importância das minorias étnicas na sustentabilidade do desenvolvimento do Reino Unido.

Na sessão do Grupo de Estudo das Mulheres foram abordadas as temáticas da igualdade de oportunidades de trabalho entre homens e mulheres na medi- 
cina e na banca, o aumento da taxa de actividade entre as esposas dos mineiros no Reino Unido em resultado da crise do sector extractivo e as consequências daí resultantes para a economia local e as novas formas de emprego cada vez mais comuns entre as mulheres, como o teletrabalho, o freelancing e as vendas por telefone.

Os jovens investigadores do Grupo de Estudo da Geografia Rural concentraram as suas atenções na sustentabilidade do turismo em espaço rural, nos financiamentos atribuídos às áreas rurais para ultrapassar atrasos estruturais e combater a pobreza e na questão da acessibilidade aos mercados de venda dos produtos agrícolas.

Como já é habitual nestas conferências, foram convidados professores de elevado prestígio internacional para realizarem conferências à hora do almoço e ao final da tarde. O Professor Ron Cooke, da Universidade de York, abordou a temática da qualidade no ensino superior, ao passo que o Professor Michael Watts, da Universidade Berkeley (EUA) se referiu ao desenvolvimento no final deste século, conjugando as ideias de Malthus e de Marx. O Professor Richard Munton realizou uma prelecção sobre a governança ambiental e as políticas que fazem a diferença, enquanto o Professor Tariq Ali, no âmbito da Antipode Lecture, se referiu aos espaços radicais.

De salientar ainda que os participantes poderiam optar pela realização de duas visitas de estudo: a primeira à National Forest, isto é uma área de floresta na região de Midlands com 200 milhas quadradas, que pretende ser um espaço onde se combina o desenvolvimento económico e a melhoria das condições ambientais através de um intenso programa de florestação; a segunda visita, mais vocacionada para os investigadores dos ambientes urbanos, focou a renovação urbana que está a ser promovida na cidade de Leicester, uma das 12 urbes mundiais considerada "Cidade do Ambiente» (Environment Cities). Um espaço de dimensões consideráveis ao longo do rio Soar foi alvo de completa reconversão funcional e paisagística, realizada através da despoluição e limpeza do leito do rio e suas margens, da reconversão de antigos armazéns em restaurantes e residências universitárias e da construção de moradias para habitação. O representante do Leicester City Council, que organizou a apresentação do projecto e que conduziu a visita pela cidade, salientou a semelhança entre estas acções de renovação urbana e as promovidas em Lisboa para a realização da EXPO 98.

A Conferência de 2000 realizar-se-á entre 4 e 8 de Janeiro na cidade inglesa de Brighton, 100 quilómetros a sul de Londres e por decisão da organização não focará nenhum tema específico. 